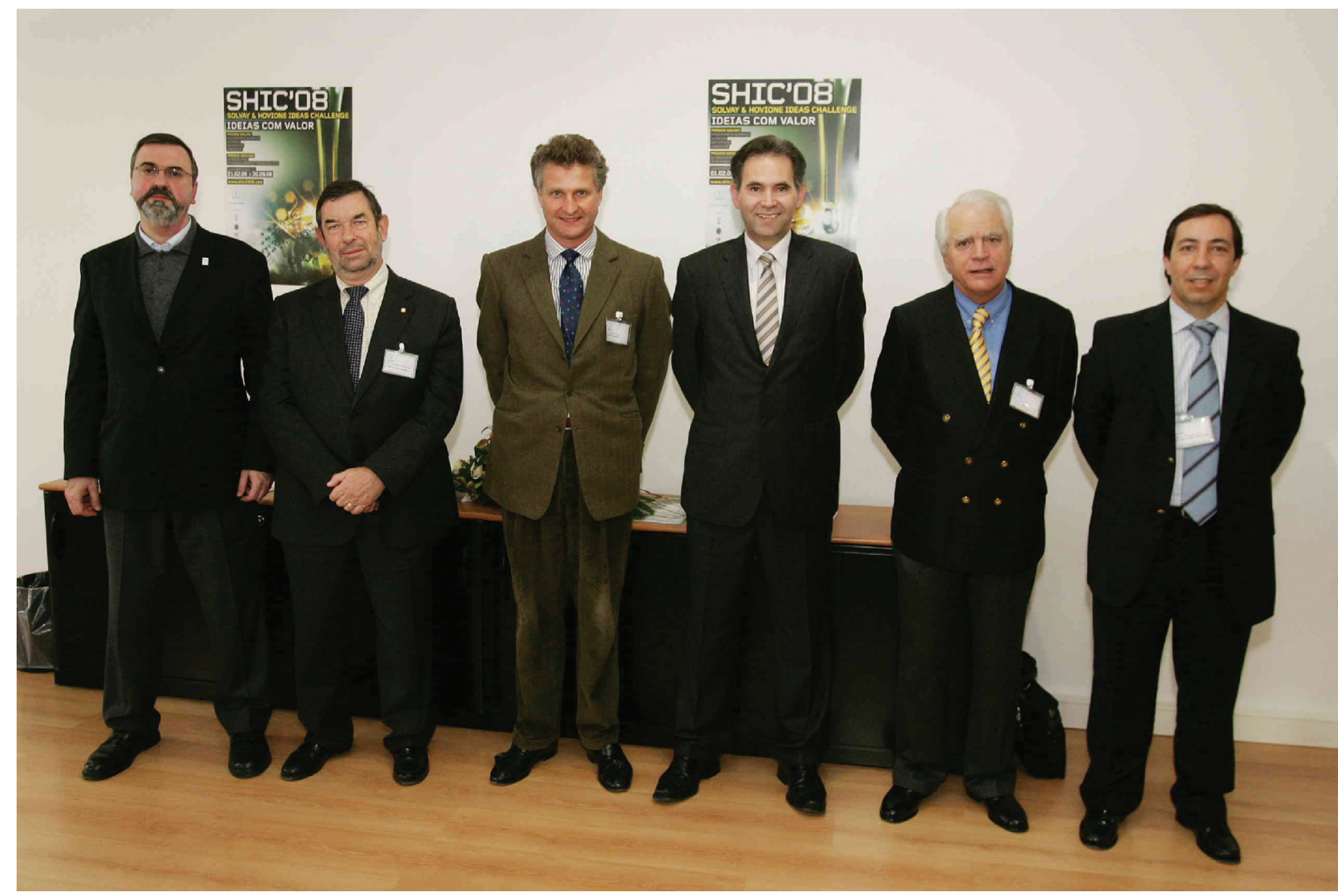

Representantes das empresas patrocinadoras e dos parceiros institucionais do Projecto SHIC'08. Ordem da esq. para dir.: Prof. Mário Berberan Santos, Vice-Presidente da Sociedade Portuguesa de Química; Eng. António Salvador Pinheiro, Presidente do Colégio de Engenharia Química da Ordem dos Engenheiros; Dr. Guy Villax, CEO da Hovione; Eng. Basilio García-Pañuela, Director da Fábrica da Solvay Portugal; Dr. Paulo Sá e Cunha, Vice-Presidente da Agência de Inovação; Dr. Paulo Amaral, Vogal do Colégio da Indústria da Ordem dos Farmacêuticos.

\title{
IX FEIRA DE CIÊNCIA DE MAdRID
}

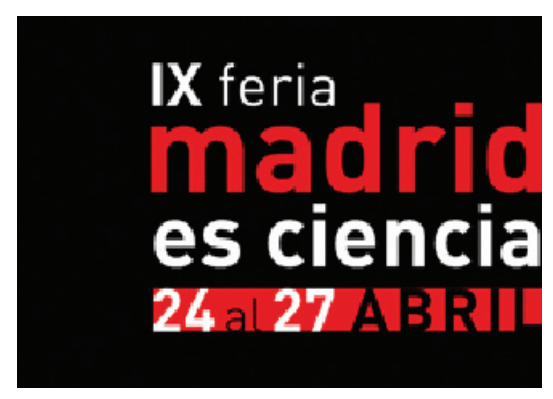

Decorreu em Madrid, de 24 a 27 de Abril, no parque de feiras IFEMA, a IX Feira de Ciência de Madrid - "Madrid es Ciencia".

A Feira de Ciência de Madrid é um evento de divulgação da Ciência de grande dimensão, que nesta edição ocupou dois pavilhões do IFEMA, numa área total de cerca de 28.000 $\mathrm{m}^{2}$, com mais de duas centenas de expositores e cerca de 600 actividades interactivas, e que ultrapassou a média de 40.000 visitantes diários (mais de 160.000 entradas registadas).
Este ano, Portugal aparecia no programa da Feira como país convidado, tendo estado representado pelo "Ciência Viva" - Agência Nacional para a Cultura Científica e Tecnológica. Ocupando um espaço de cerca de $50 \mathrm{~m}^{2}$ num local central da Feira, a representação de Portugal teve como destaques especiais as actividades " $\mathrm{A}$ Cozinha é um Laboratório" e "Química por Tabela", ambas concebidas por sócios da SPQ, docentes do Departamento de Química da Universidade de Aveiro, para a Fábrica Centro Ciência Viva de Aveiro.

O "Química por Tabela", além de ter estado em demonstração contínua durante os quatro dias, foi apresentado na sua versão de espectáculo no auditório da Feira. A representação portuguesa incluiu ainda "Hologramas desenhados à mão" (actividade desenvolvida pelo Departamento de Física da Universidade de Aveiro e que obteve um prémio internacional de comunicação de ciência), "Mãos no Gelo", "Quem é o Assassino?" e "Jogos Matemáticos".

De acordo com a directora do Ciência Viva, Ana Noronha, a organização da Feira fez questão de referenciar muito positivamente a participação de Portugal, destacando-a como a melhor de país convidado de sempre, pela qualidade e profissionalismo da representação e pelo cuidado que a equipa teve em interagir e fazer-se entender pelo público.

A IX Feira de Ciência de Madrid contou com a participação de um número elevado de universidades e institutos de ensino superior - com evidente preocupação na divulgação dos seus cursos e na captação de futuros alunos - assim como diversas empresas, entidades públicas regionais e nacionais, museus e organizações não governamentais. No entanto, muita da riqueza e diversidade da Feira 
resulta da já habitual participação de um elevado número de escolas, cuja representação é assegurada por equipas empenhadas de alunos de todas as idades [a Comunidade Autonómica de Madrid apoia financeiramente a participação das escolas e concede dispensa de aulas durante os dois dias úteis da Feira]. Embora sem a imagem profissional e os meios pro- mocionais das empresas, as escolas destacam-se pela criatividade dos temas propostos e pelo empenho e rigor dos seus "cientistas de palmo e meio".

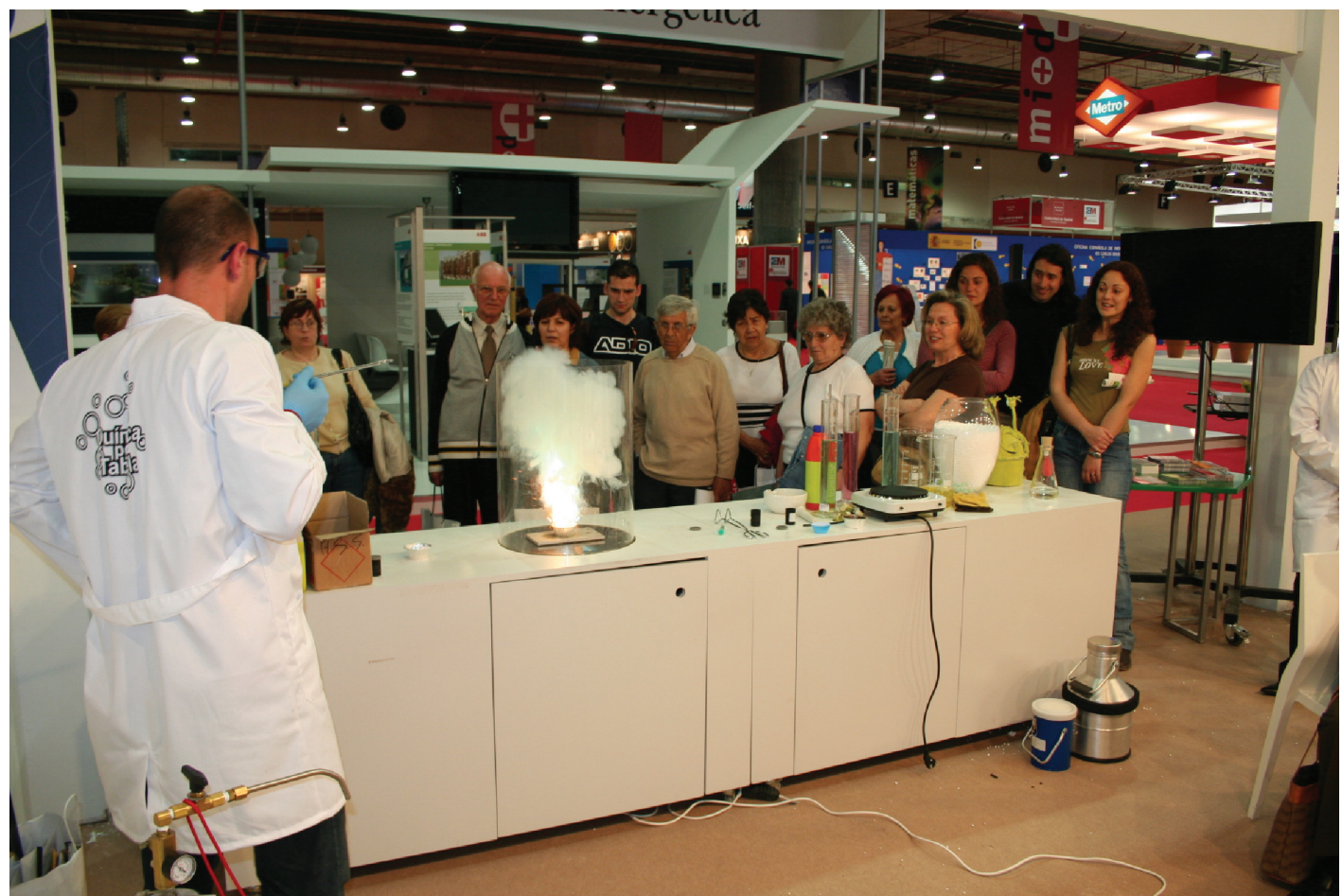

"Química por Tabela" é uma actividade da Fábrica criada com base no trabalho de Paulo Ribeiro Claro e Brian Goodfellow do Departamento de Química da Universidade de Aveiro onde, a partir de uma sequência de reacções químicas visualmente apelativas, surpreendentes, ou mesmo espectaculares, conjugadas com artes cénicas de luz e som, se proporcionam momentos de comunicação de ciência.

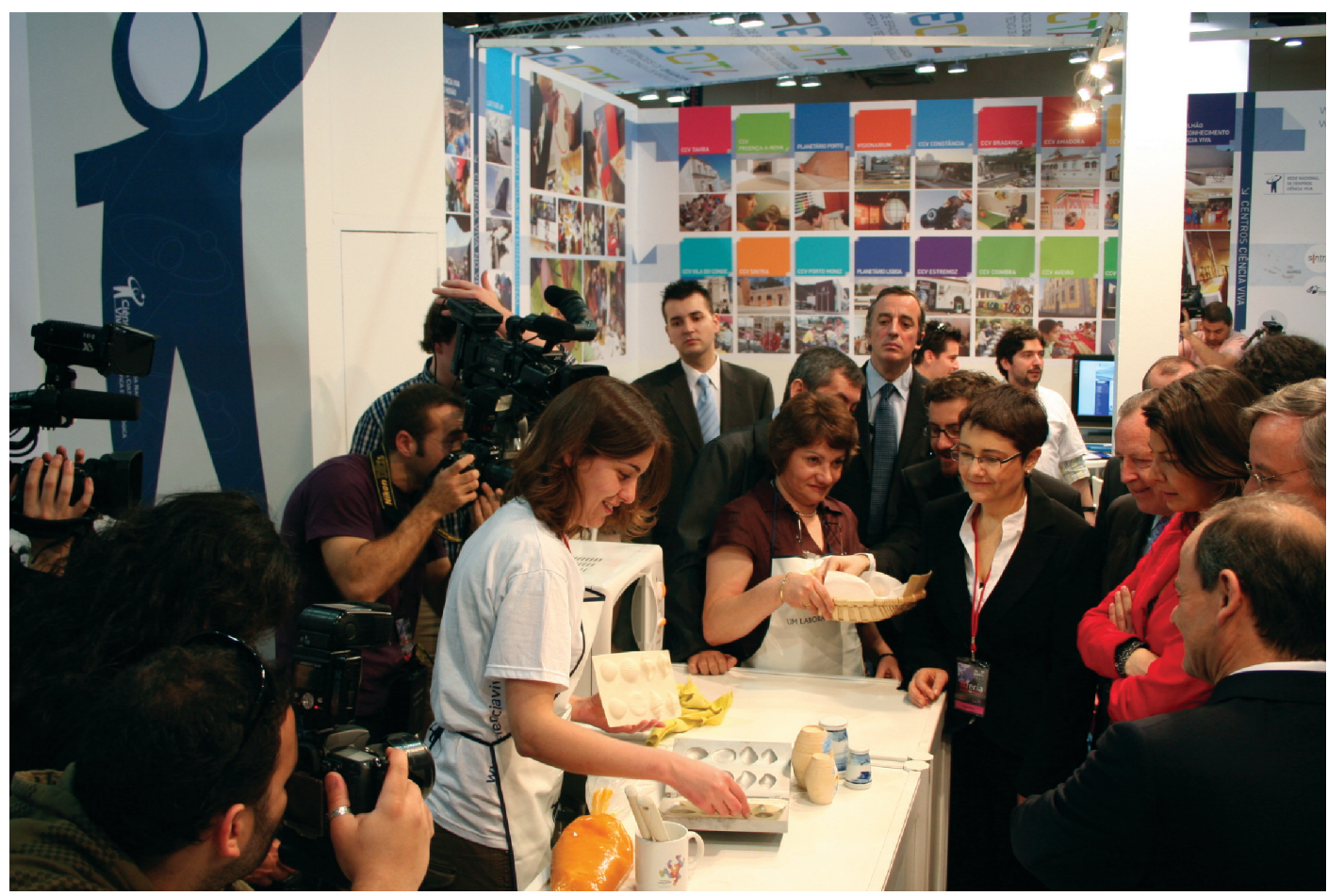

"A Cozinha é um Laboratório" é uma actividade da Fábrica que convida a descobrir a ciência e a tecnologia que existe em espaços tão familiares como a cozinha das nossas casas. É o local onde "pôr as mãos na massa" encontra a sua aplicação mais literal. Observando e testando, o visitante fica a conhecer melhor os processos subjacentes às transformações químicas e bioquímicas que ocorrem nos alimentos quando os preparamos. 